\title{
Effect of Feed Rate on Surface Roughness in Abrasive Waterjet Machining of Jute Fibre Reinforced Polyester Composites
}

\author{
Kalirasu S, Rajini N, Rajesh S, Jessy Michla J. R, Sathish kumar S.
}

\begin{abstract}
The common fiber strengthened composite are as a rule progressively utilized in different applications like space, flying machine, marine, building and car segment on account of their prevalent physical and mechanical properties despite the fact that they are somewhat expensive. AWJM speaks to a worldwide adaptable instrument supporting the machining of every normal material that are with no harm by straight contact with water. In this present work plans to explore jute fiber strengthened unsaturated polyester resin composite material investigating surface Roughness by changing three parameters, for example, Pressure, Standoff distance and Feed rate an ideal state of the material can be found and furthermore investigation of the cut surface geography after grating water stream machining. Rough utilized for cutting is garnet 80 mesh abrasive particles. It catalyzes the cutting and gives phenomenal surface completion.
\end{abstract}

Keywords: Jute Fiber, Surface Roughness, Abrasive water jet Machining

\section{INTRODUCTION}

Progressed machining is the developing innovation contributed in various building segments in the field of aviation, marine, design and vehicle areas. In mechanically created world, cutting of metals, steels and combinations are simple yet machining regular composite fibre is an extreme occupation in light of warm impact happens in the material. Biodegradable materials have shown up greater scope among the researchers as well as in the industrial areas [1]. More commonly natural fibers such as aramid, basalt, coconut sheath, banana fiber, glass, etc. are used for its better properties. [2]. In some cases, hybrid composites for example Basalt-Curaua fiber is used for its enrichment mechanical properties without affecting the durability [3]. this exploration work dominatingly covers on surface harshness on JF/UPR composites. Explored on rigidity on regular filaments and ordered into two gatherings and jute is characterized into elite characteristic fibre [4].

Revised Manuscript Received on December 5, 2019

S.Kalirasu, Associate Professor, Department of Mechanical Engineering, Kalasalingam Academy of Research and Education, Krishnankoil-626126, Tamilnadu, India. Email: kalirasu.s@ gmail.com

N. Rajini, Professor, Department of Mechanical Engineering, Kalasalingam Academy of Research and Education, Krishnankoil-626126, Tamilnadu, India. Email: rajiniklu@gmail.com

S. Rajesh, Associate Professor, Department of Mechanical Engineering, Kalasalingam Academy of Research and Education, Krishnankoil-626126, Tamilnadu, India. Email: s.rajesh@klu.ac.in

J. R. Jessy Michla, Research Scholar, Department of Mechanical Engineering, Kalasalingam Academy of Research and Education, Krishnankoil-626126, Tamilnadu, India. Email: jes.michla@ gmail.com

S. Sathish kumar, Assistant Professor, Department of Automobile Engineering, Dr. Mahalingam College of Engineering and Technology, Pollachi-642003, Tamilnadu, India. Email: Satu_aue@yahoo.co.in
Explored mechanical properties of common strands and said that jute material is useful for its flexural property. Numerous works have been tended to utilizing AWJM for fiber fortified polyester composites [5, 6, and 7]. S. Abrate studied the benefits and negative marks of customary and different progressed machining process on composite materials concerning heat affectability, harm and instrument wear [8]. Distributed a detail consider on grating water stream machining process on glass/epoxy composite cover and affirmed that by expanding the active vitality of AWJM process produce better cut [9]. Inferred that with medium transverse speed satisfactory unpleasantness will be picked up and diminish of grating particles somewhat changes the surface roughness [10]. Inquired about on surface unpleasantness on aluminum combination 7075 and inferred that at low weight and low $S_{d}$ surface harshness of the material is improved [11]. Inquired about on tempered steel and inferred that high transverse speed prompts less expulsion of material and abatement in $S_{d}$ and $V_{f}$ prompts improve machining execution and furthermore depicts that the determination of spout and opening will improve the nature of the kerf [12]. Nearness of harms in types of holes, edges, broken filaments and inserted rough particles by SEM analysis are carried out [13]. Cease that while machining $\mathrm{SiC}$ and $\mathrm{Al}_{2} \mathrm{O}_{3}$ by $\mathrm{AWJM}$ when $\mathrm{S}_{\mathrm{d}}$ diminishes decrease cut increments. Whenever $\mathrm{P}$ and $\mathrm{S}_{\mathrm{d}}$ builds decrease cut abatements. In the event that $\mathrm{V}_{\mathrm{f}}$ is more decrease cut increases [14]. Examined multidirectional CFRP Laminates on AWJM and came about that for better surface quality high weight, low $\mathrm{V}_{\mathrm{f}}$ and little $\mathrm{S}_{\mathrm{d}}$ is recommended [15]. Moreover, different techniques are used to optimise the process parameters theoretically like Taguchi method, fuzzy logic, ANOVA, etc. [16]. Here, a practical approach is considered to minimise the $\mathrm{Ra}$ of the fabricated composite.

\section{EXPERIMENTAL DETAILS}

\section{A. Materials Used}

In this method, UPR is used as matrix, JF as reinforcement, methyl-ethyl-ketone peroxide (MEKP) as catalyst and cobalt napthenate as accelerator respectively. These products are delivered from vasavibala resin $(\mathrm{P}) \mathrm{Ltd}$, Chennai. While Purchasing of JF is from GVR enterprises, Madurai. 


\section{Effect of Feed Rate on Surface Roughness in Abrasive Waterjet Machining of Jute Fibre Reinforced Polyester Composites}

\section{B. Equipment Details}

It has the possibility to cut the materials of approximately with speed of $0.25 \mathrm{~mm} / \mathrm{s}$ without producing any toxic gas, dust or any other thermal accomplishments. The schematic diagram of abrasive water jet machining is shown in Figure 1. The diameter of the nozzle is about $0.76 \mathrm{~mm}$ and the sample thickness of $3 \mathrm{~mm}$ composites laminates are used. Other parameters including the pressure limit from $150 \mathrm{MPa}$ to $250 \mathrm{MPa}, \mathrm{S}_{\mathrm{d}}$ is about $1 \mathrm{~mm}$ to $3 \mathrm{~mm}$ and the fluid velocity or the $V_{\mathrm{f}}$ is of $20 \mathrm{~mm}$ to $40 \mathrm{~mm}$.



Fig. 1. A schematic diagram of AWJM

\section{Fabrication Techniques}

JF/UPR composites are manufactured by Hand layup technique is shown in Figure 2. The density of the jute fiber is of $1.5 \mathrm{~g} / \mathrm{cm}^{3}$. Hand layup manufacture forms include some type of embellishment, to shape the sap and fortification. A form apparatus is required to give the unformed resin/fiber that blends its shape before and amid fix. At first, cleaning the surface plate with wax helps to evade the matrix adhesion. Each layer of JF is of 10 gram in weight and is layered with five successions. The polyester resin was blended with 1.5 wt. \% of the impetus and 1.5 wt. $\%$ of the quickening agent before it was connected on every fiber surface. Finally, layer by layer with resin coating form of material was placed on the top of the mould and subjected to cure over one day under room temperature. After 24 hours of treatment, JF/UPR composite plate (30wt $\%)$ of thickness ( $3 \mathrm{~mm})$ is obtained.



Fig. 2. Composite Fabrication by Hand layup technique

\section{AWJ Machining of JF/UPR Composites}

Abrasive feeder in AWJM as shown in Figure 3(a) and Figure 3(b) denote the AWJM cutting of JF/UPR composite laminate as per parameter selection.



ABR.ASIVE FLOW PIPE

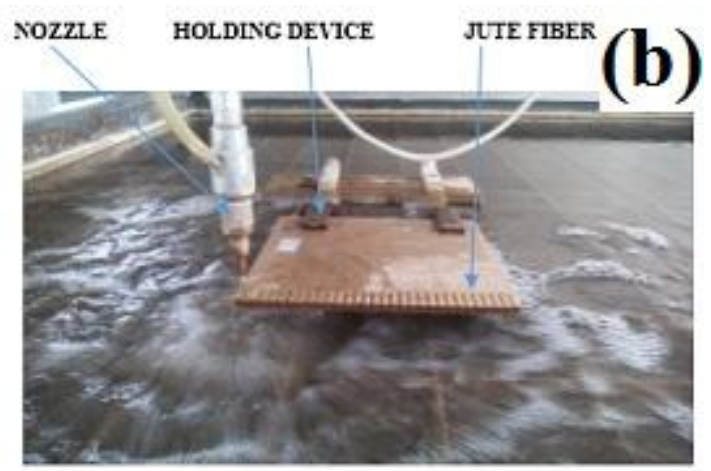

Fig. 3. (a) Abrasive Feeder (b) Nozzle setup with JF/UPR composite

\section{E. Surface Roughness test}

Once after machining the Ra of the fabricated composite machined surface is measured using Surftest SJ-301 (Make: Mitutoyo) profilometer with the speed of $0.25 \mathrm{~mm} / \mathrm{s}$. The maximum measuring limit of the profilometer is about 350 $\mu \mathrm{m}$. First of all, adjusting the probe by touching the plate and the readings are taken down based on the various intervals. Likewise, the values are measured and marked for various optimal parameters. The average of two Ra values is reported. Thus by recording the optimum condition of all materials has been analyzed.

Figure 4 (a) shows the measurement of Ra, (b) cutting direction and the arrow indicates the side of probe measures the work and (c) SEM analysis of cutting surface.

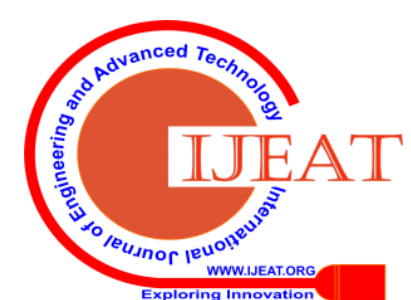



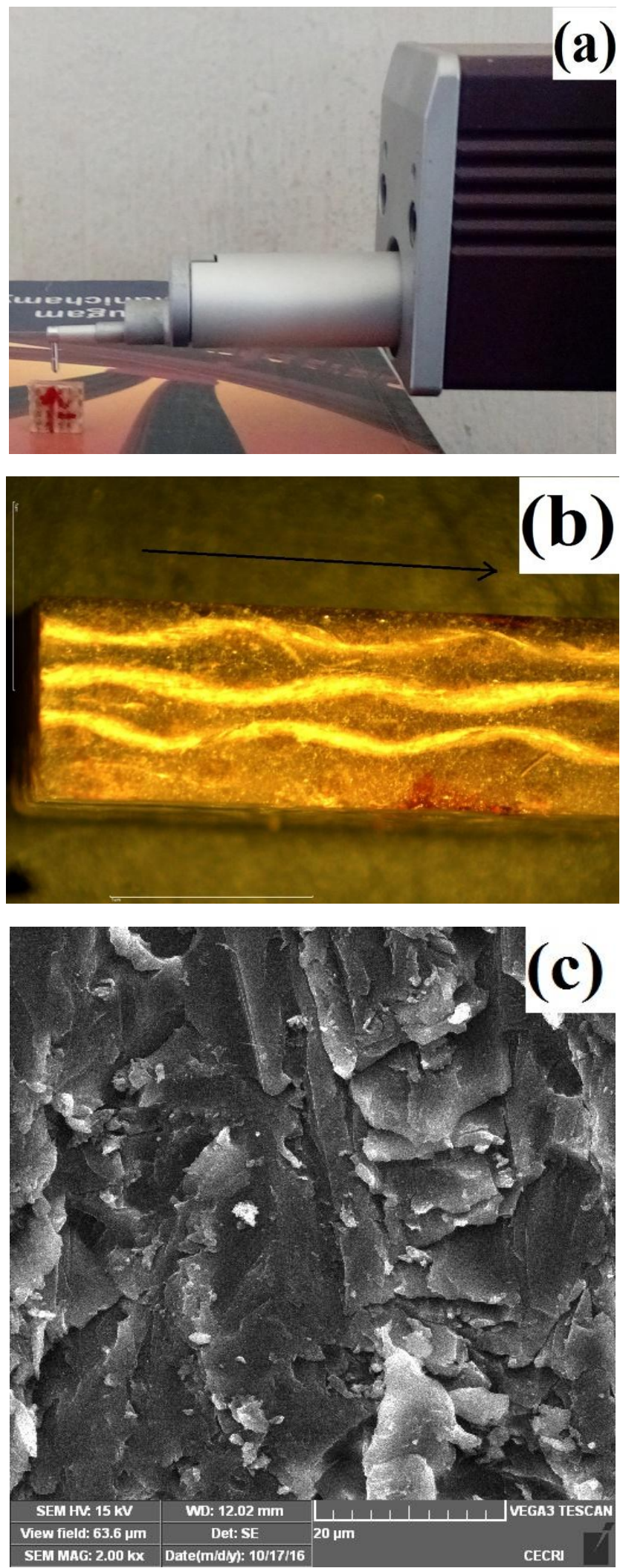

Fig. 4. (a) Roughness measurement (b) Cutting direction and (c) SEM image of cutting surface

\section{RESULTS AND DISCUSSIONS}

From this figure, the $R_{a}$ is calculated by changing the $V_{f}$ and maintaining the pressure and $S_{d}$ as constant say (150 $\mathrm{MPa}$ and $1 \mathrm{~mm}$ ). Accordingly increasing the $\mathrm{V}_{\mathrm{f}}$, the surface roughness slightly increases even after keeping the $S_{d}$ and pressure the same.
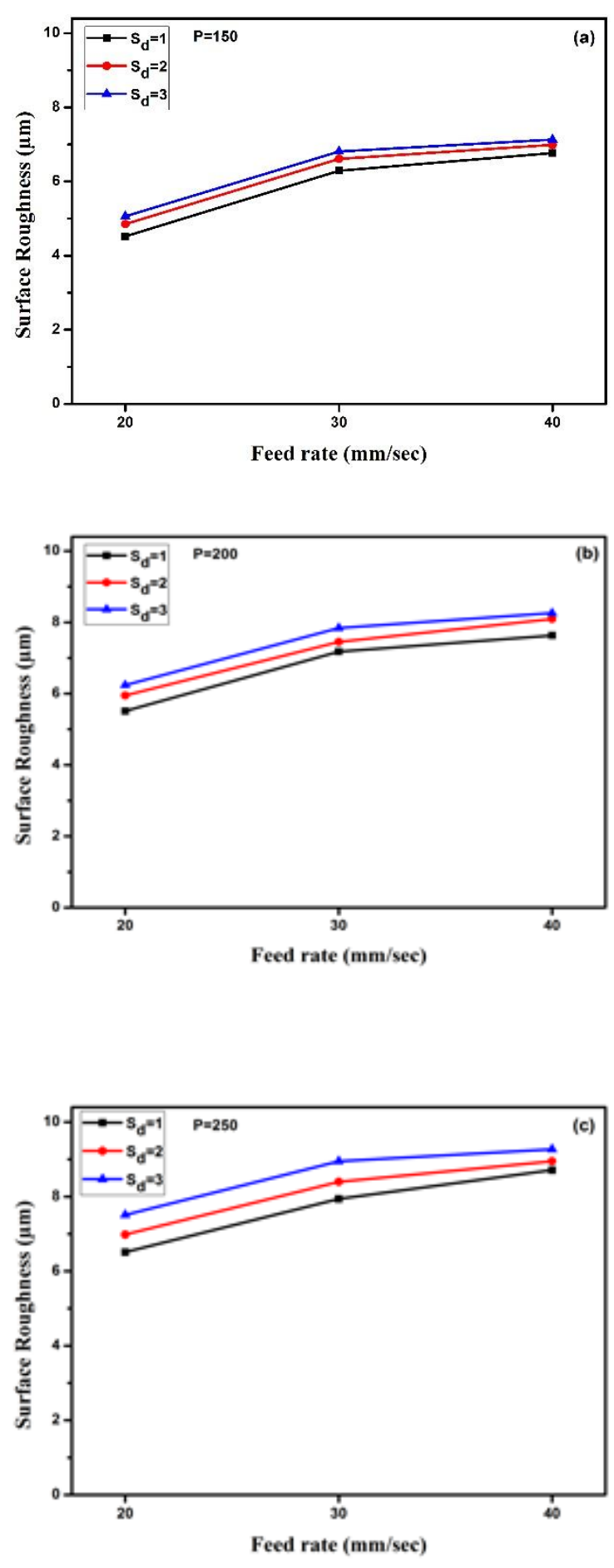

Fig. 5. Surface roughness with effect of feed rate (a) 150 pressure (b) 200 pressure and (c) 250 pressure

In the figure 5 ( $b$ and $c$ ) represents similar process for the pressure and $S_{\mathrm{d}}$ of $150 \mathrm{MPa}, 200 \mathrm{MPa}, 250 \mathrm{MPa}$ and $1 \mathrm{~mm}$, $2 \mathrm{~mm}, 3 \mathrm{~mm}$ and by varying the feed rate the surface roughness tend to increase with increase in pressure and $S_{d}$. Finally, by comparing the three graphs, it can be concluded that when $S_{d}$ and $V_{f}$ is minimum the surface roughness of the material is low.

Published By: 


\section{Effect of Feed Rate on Surface Roughness in Abrasive Waterjet Machining of Jute Fibre Reinforced Polyester Composites}

\section{IV.CONCLUSIONS}

This experimental output is based on the surface roughness, pressure and feed rate and all such process parameters are studies and analyzed. Regarding the optimal parameters, the feed rate has the possibility to affect the outcome. It is cleared that from the graph that as $\mathrm{P}=150 \mathrm{MPa}, \mathrm{S}_{\mathrm{d}}=1$ $\mathrm{mm}, \mathrm{V}_{\mathrm{f}}=20 \mathrm{~mm} / \mathrm{sec}$ is the optimum condition of $\mathrm{R}_{\mathrm{a}}$ in JF/UPR material.

\section{REFERENCES}

1. M. P. Groover, "Fundamental of modern manufacturing (2nd ed.)," Hoboken, NJ: John Wiley \& Sons, Inc., 2004.

2. V. Dhand, G. Mittal, K.Y. Rhee, S. J. Park, D. Hui, "A short review on basalt fiber reinforced polymer composites," Compos. Part B, vol. 73, 2015, pp. 166-180.

3. T. Premkumar, I. Siva, S. Rajesh, J. T. Winowlin Jappes, Sandro Campos Amico, "Investigation to appraise the abrasive water jet response of curaua/basalt hybrid polyester composites," Int. J. Manuf. Mater. Mechanical Engineering, Vol. 9, 2019, pp. 17.

4. F. Maria, Thatiana Victorino Castro Pereira, G. Otavio, Flavio de Andrade silva, Romildo Dias Toledo Filho "The effect of fibre morphology on the tensile strength of natural fibers," J. Mater. Res. Technol., vol. 2(2), 2013, pp. 149-157.

5. C. Elanchezhian, B. Vijaya Ramnath, G. Ramakrishnan, M. Rajendrakumar, V. Naveenkumar, M. K. Saravanakumar. "Review on mechanical properties of natural fiber composites," Mater. Today Proc., vol. 5, 2018, pp. 1785-1790.

6. S. Kalirasu, N. Rajini, N. Bharathsagar, D. Mahesh kumar, A. Gomathisankar, "Studies of Abrasive Water Jet Machining (AWJM) Parameters on Banana/Polyester Composites Using Robust Design Concept," Journal of Applied Mechanics and Materials, vol. 787, 2015, pp. 573-577.

7. S. Kalirasu, N. Rajini N, J. T. Winowlin Jappes, M. Uthayakumar, S. Rajesh. "Mechanical and machining performance of glass and coconut sheath fibre polyester composites using AWJM," J. Reinf. Plast. Comp., vol. 34 (7), 2015, pp. 564-580.

8. S. Abrate, D. Walton, "Machining of composite materials part-II: Non-traditional methods," Compos. Manuf., vol.3 (2), 1992, pp. 8594.

9. M. A. Azmir, A. K. Ahsan, "A study of abrasive water jet machining process on glass/epoxy composite laminate - A review”. Journal of material processing technology," vol. 209, 2009, pp. 6168-6173.

10. Derzija Begic-Hajdarevic, Ahmet Cekic, Muhamed Mehmedovic and Almina Djelmic, "Experimental study on surface roughness in abrasive water jet cutting,” Journal of Procedia Eng., vol.100, 2015, pp. 349399.

11. Tarek M. Ahmed, Ahmed Mesalamy, Amro Youssef and Tawfik T. El Midany, "Improving surface roughness of abrasive waterjet cutting process by using statistical modeling - A review," J. Manuf. Sci. technol., vol. 22, 2018, pp. 30-36.

12. S. B. Supriya, S. Srinivas, "Machinability Studies on Stainless steel by abrasive water jet - Review," Mater. Today Proc., vol. 5, 2018, pp. 2871-2876.

13. Akshay Hejjaji, Redouane Zitoune, Laurent crouzeix, Sabine Le Roux and Francis Collombet, "Surface and machining induced damage characterization of abrasive water jet milled carbon/epoxy composite specimens and their impact on tensile behavior - A review," Journal on wear, vol. 376-377, 2017, pp. 1356-1364.

14. A. A. Khan and M. M. Haque. "Performance of different abrasive materials during abrasive water jet machining of glass - A review". J. Mater. Process. Technol., vol.404-407, 2007, pp.191.

15. M. El-Hofy, M. O. Helmy, G. Escobar-Palafox, K. Kerrigan, R. Scaife and H. El-Hofy, "Abrasive water jet machining of multidirectional CFRP Laminates,” Journal of Procedia CIRP, vol. 68, 2018, pp. 535-540.
16. Jagadish, Sumit Bhowmik, Amitava Ray, "Prediction of surface roughness quality of green abrasive water jet machining: a soft computing approach," J. Intell. Manuf., 2015, DOI 10.1007/s10845015-1169-7.

\section{AUTHORS PROFILE}

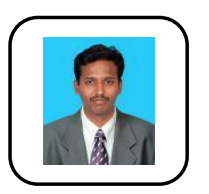

Dr. S. Kalirasu obtained his Bachelor's degree in Automobile engineering from K.L.N.College of Engineering; Madurai affiliated to Anna University, Chennai in 2009. He was awarded his Master's degree in CAD/CAM from Kalasalingam University, Krishnankoil in 2012. Then he was awarded his $\mathrm{PhD}$ in Mechanical Engineering from Kalasalingam Academy of Research and Education, Krishnankoil in 2018, He has published 10 international journals and also published more than 10 papers in International Conference proceedings. His research interest is on the fabrication of natural fiber composites and machining studies. He was an Editor for the third International Conference on Advanced Manufacturing and Automation (INCAMA) 2018. Now he is working as an Associate professor in the Department of Mechanical Engineering, Kalasalingam Academy of Research and Education since, 2012 .

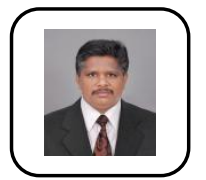

Dr. N. Rajini obtained his Bachelor's degree in Mechanical Engineering from Manonmaniam Sundaranar University, Tirunelveli in 1999. He was awarded his Master's degree in Engineering Design from Anna University, Chennai in 2004. Then he completed his $\mathrm{PhD}$ in Composite Materials from Kalasalingam University, Krishnankoil in 2013 and then his post-doctoral fellowship in Ghen University, Belgium in 2015. He was a visiting scientist at INTROP, Malaysia and KMUTNB, Bangkok. He is a life time member of ISTE. He brings to his position in a well-balanced background in polymers. He has published more than 70 international journals and also published more than 30 papers in International Conference proceedings. He was a Co-Principal Investigator for a funded project of Tamilnadu State Council for Science and Technology. Currently, he is working as a Professor in the Department of Mechanical Engineering, Kalasalingam Academy of Research and Education since, 2004

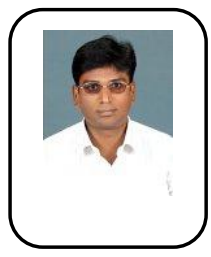

Dr. S. Rajesh obtained his Bachelor's degree in Mechanical Engineering from Alagappa Chettiar College of Engineering and Technology; Karaikudi affiliated to Madurai Kamaraj University (2002) and completed his Master's degree in Computer Aided Design from the Alagappa Chettiar College of Engineering and Technology, Karaikudi affiliated to Anna University Chennai (2008). Then he was awarded his PhD in Mechanical Engineering from Kalasalingam Academy of Research and Education, Krishnankoil in 2014. He published more than 10 papers in the reputed journals and also published more than 17 international conference papers. Presently, he is working as an Associate Professor \& Head of Department of Mechanical Engineering, Kalasalingam Academy of Research and Education with more than 15 years of teaching expertise.

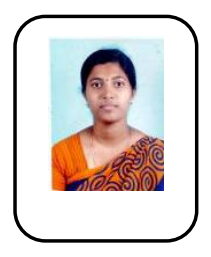

Mrs. J. R. Jessy Michla obtained her Bachelor's degree in Aeronautical Engineering from Vel Tech Engineering College, Chennai with the university rank - 15 and Master's degree in Computer Aided Design from Government College of Engineering, Salem with a top rank score. Currently, she is pursuing her $\mathrm{PhD}$ in Mechanical Engineering, Kalasalingam Academy of Research and Education.



Mr. S. Sathiskumar obtained his Bachelor's degree in Automobile engineering 2009 and awarded his Master's degree in CAD/CAM from K.L.N. College of Engineering, Madurai, affiliated to Anna University, Chennai in 2011. He is a member of ISTE. Now he is working as an Assistant professor in Automobile Engineering Department, Dr. Mahalingam College of Engineering and Technology, Pollachi from 2014. 